\title{
Trans-ancestry genome-wide association study of gestational diabetes mellitus highlights genetic links with type 2 diabetes
}

\begin{abstract}
Natalia Pervjakova ${ }^{1, *}$, Gunn-Helen Moen $^{2-5,{ }^{*}}$, Maria-Carolina Borges ${ }^{5-6,{ }^{*}}$, Teresa Ferreira ${ }^{7,}$, , James P Cook $^{8}$, Catherine Allard ${ }^{9}$, Robin N Beaumont ${ }^{10}$, Mickaël Canouil ${ }^{11-12}$, Gad Hatem ${ }^{13}$, Anni Heiskala ${ }^{14}$, Anni Joensuu ${ }^{15-16}$, Ville Karhunen ${ }^{14,17}$, Soo Heon Kwak ${ }^{18}$, Frederick TJ Lin ${ }^{19}$, Jun Liu ${ }^{20-21}$, Sheryl RifasShiman $^{22}$, Gudmar Thorleifsson ${ }^{23}$, Toby Andrew ${ }^{11-12,24}$, Juha Auvinen ${ }^{14}$, Bishwajit Bhowmik ${ }^{25}$, Amélie Bonnefond ${ }^{11-12,24}$, Fabien Delahaye ${ }^{11-12}$, Ayse Demirkan ${ }^{20,26}$, Philippe Froguel ${ }^{11-12,24}$, Kadri HallerKikkatalo ${ }^{27}$, Hildur Hardardottir $28-29$, Sandra Hummel ${ }^{30-31}$, Akhtar Hussain ${ }^{25,32}$, Eero Kajantie ${ }^{33-35}$, Elina Keikkala ${ }^{33-34}$, Amna Khamis ${ }^{11-12,24}$, Jari Lahti ${ }^{36}$, Tove Lekva ${ }^{37}$, Sanna Mustaniemi ${ }^{33-34}$, Christine Sommer $^{38}$, Aili Tagoma ${ }^{27}$, Evangelia Tzala ${ }^{17}$, Raivo Uibo ${ }^{27}$, Marja Vääräsmäkij ${ }^{34,39}$, Pia M Villa ${ }^{40-41}$, Kåre I Birkeland ${ }^{2,42}$, Luigi Bouchard ${ }^{43-44}$, Cornelia M Duijn ${ }^{20-21}$, Sarah Finer ${ }^{45}$, Leif Groop ${ }^{13,46}$, Esa Hämäläinen ${ }^{47}$, Geoffrey M Hayes ${ }^{19,48-49}$, Graham A Hitman ${ }^{45}$, Hak C Jang ${ }^{50-51}$, Marjo-Riitta Järvelin ${ }^{14,17}$, Anne Karen Jenum ${ }^{52}$, Hannele Laivuori ${ }^{46,53-54}$, Olle Melander ${ }^{13}$, Emily Oken ${ }^{22}$, Kyong Soo Park ${ }^{18,51,55}$, Patrice Perron ${ }^{9,56}$, Rashmi B Prasad ${ }^{13}$, Elisabeth Qvigstad ${ }^{38,57}$, Sylvain Sebert ${ }^{14}$, Kari Stefansson ${ }^{23,58}$, Valgerdur Steinthorsdottir ${ }^{23}$, Tiinamaija Tuomi ${ }^{46,59-61}$, Marie-France Hivert ${ }^{22,56,62}$, Paul W Franks ${ }^{63-64}$, Mark I McCarthy ${ }^{65-66, \phi}$, Cecilia M Lindgren ${ }^{7,66-67}$, Rachel M Freathy ${ }^{10,{ }^{\dagger}}$, Deborah A Lawlor ${ }^{5-6,68,{ }^{+}}$, Andrew P Morris ${ }^{69,}{ }^{+}$, Reedik Mägi ${ }^{1,+}$.
\end{abstract}

1)Estonian Genome Centre, Institute of Genomics, University of Tartu, Tartu, 51010, Estonia. 2)Institute of Clinical Medicine, Faculty of Medicine, University of Oslo, Oslo, Norway. 3)The University of Queensland Diamantina Institute, The University of Queensland, Woolloongabba, QLD 4102, Australia. 4)K.G. Jebsen Center for Genetic Epidemiology, Department of Public Health and Nursing, NTNU, Norwegian University of Science and Technology, Trondheim, Norway. 5)Population Health Science, Bristol Medical School, University of Bristol, Bristol, UK. 6)MRC Integrative Epidemiology Unit, University of Bristol, Bristol, UK. 7)Big Data Institute, Li Ka Shing Center for Health for Health Information and Discovery, Oxford University, Oxford, UK. 8)Department of Health Data Science, University of Liverpool, Liverpool, UK. 9)Centre de recherche du Centre hospitalier universitaire de Sherbrooke (CRCHUS), University of Sherbrook, Québec, Canada. 10)Institute of Biomedical and Clinical Science, College of Medicine and Health, University of Exeter, Exeter, UK. 11)Inserm U1283, CNRS UMR 8199, European Genomic Institute for Diabetes, Institut Pasteur de Lille, Lille, F-59000, France. 12)University of Lille, Lille University Hospital, Lille, F-59000, France. 13)Lund University Diabetes Centre, Department of Clinical Sciences, Lund University, Skåne University Hospital, SE20502 Malmö, Sweden. 14)Centre for life-course health research, Faculty of Medicine, University of Oulu, Oulu, Finland. 15)Department of Public Health Solutions, Finnish Institute for Health and Welfare, Helsinki, Finland. 16)Research Program for Clinical and Molecular Metabolism, Faculty of Medicine, University of Helsinki, Helsinki, Finland. 17)School of Public Health, Dept of Epidemiology and Biostatistics, Imperial College London, St Mary's Hospital, London, UK. 18)Department of Internal Medicine, Seoul National University Hospital, Seoul, Republic of Korea. 19)Division of Endocrinology, Metabolism, and Molecular Medicine, Department of Medicine, Northwestern University Feinberg School of Medicine, Chicago, IL 60611, USA. 20)Department of Epidemiology, Erasmus Medical Center, Rotterdam, the Netherlands. 21)Nuffield Department of Population Health, University of Oxford, Oxford, UK. 22)Department of Population Medicine, Harvard Medical School and Harvard Pilgrim Health Care Institute, Boston, MA, USA. 23)deCODE genetics/Amgen, Inc., Reykjavik, Iceland. 24)Department of Metabolism, Digestion and Reproduction, Imperial College London, London, UK. 25)Centre of Global Health Research, Diabetic Association of Bangladesh, Dhaka, Bangladesh. 26)Section of Statistical Multi-omics, Department of Clinical and Experimental research, University of Surrey, Guildford, Surrey, UK. 27)Department of Immunology, Institute of Biomedicine and Translational Medicine, University of Tartu, Tartu, Estonia. 28)Faculty of Medicine, University of Iceland, Reykjavik, Iceland. 29)Livio Reykjavik, Reykjavik, Iceland 30)Institute of Diabetes Research, Helmholtz Zentrum München, German Research Center for Environmental Health, Munich-Neuherberg, Germany.

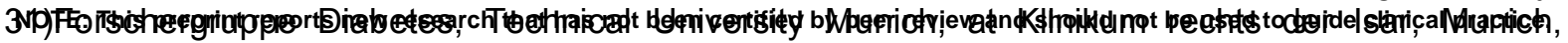



medRxiv preprint doi: https://doi.org/10.1101/2021.10.11.21264235; this version posted October $14,2021$. The copyright holder for this
preprint (which was not certified by peer review) is the author/funder, who has granted medRxiv a license to display the preprint in perpetuity.

It is made available under a CC-BY 4.0 International license .

Germany. 32)Nord University, Faculty of Health Sciences, Bodø, Norway. 33)Finnish Institute for Health and Welfare, Population Health Unit, Helsinki and Oulu, Finland. 34)PEDEGO Research Unit, MRC Oulu, Oulu University Hospital and University of Oulu, Oulu, Finland. 35)Department of Clinical and Molecular Medicine, Norwegian University of Science and Technology, Trondheim, Norway. 36)Department of Psychology and Logopedics, University of Helsinki, Helsinki, Finland. 37)Research Institute of Internal Medicine, Oslo University Hospital, Oslo, Norway. 38)Dept. Of Endocrinology, Morbid Obesity and Preventive Medicine, Oslo University Hospital, Oslo, Norway. 39)Finnish Institute for Health and Welfare, Population Health Unit, Helsinki and Oulu, Finland 40)Department of Obstetrics and Gynaecology, University of Helsinki and Helsinki University Hospital, Helsinki, Finland. 41)Hyvinkää Hospital, Helsinki and Uusimaa Hospital District, Hyvinkää, Finland. 42)Department of Transplantation Medicine, Oslo University Hospital, Oslo, Norway. 43)Department of Biochemistry and Functional Genomics, Faculty of Medicine and Health Sciences, University of Sherbrook, Québec, Canada. 44)Department of Medical Biology, Centre intégré universitaire de santé et de services sociaux du Saguenay-Lac-St-Jean - Hôpital de Chicoutimi, Québec, Canada. 45)Centre for Genomics and Child Health, Blizard Institute, Barts and the London School of Medicine and Dentistry, Queen Mary University of London, London, UK. 46)Institute for Molecular Medicine Finland (FIMM), Helsinki Institute of Life Science, University of Helsinki, Helsinki, Finland. 47)Department of Clinical Chemistry, University of Eastern Finland, Kuopio, Finland. 48)Center for Genetic Medicine, Northwestern University Feinberg School of Medicine, Chicago, IL 60611, USA. 49)Department of Anthropology, Northwestern University, Evanston, IL 60208, USA. 50)Department of Internal Medicine, Seoul National University Bundang Hospital, Seongnam, Republic of Korea. 51)Department of Internal Medicine, Seoul National University College of Medicine, Seoul, Republic of Korea. 52)General Practice Research Unit (AFE), Department of General Practice, Institute of Health and Society, Faculty of Medicine, University of Oslo, Post Box 1130 Blindern, 0318, Oslo, Norway. 53)Department of Obstetrics and Gynecology, Tampere University Hospital and Faculty of Medicine and Health Technology, Center for Child, Adolescent, and Maternal Health, Tampere University, Tampere Finland. 54)Medical and Clinical Genetics, University of Helsinki and Helsinki University Hospital, Helsinki, Finland. 55)Department of Molecular Medicine and Biopharmaceutical Sciences, Graduate School of Convergence Science and Technology, Seoul National University, Seoul, Republic of Korea 56)Department of Medicine, Faculty of Medicine and Health Sciences, University of Sherbrook, Québec, Canada. 57)Institute of Clinical Medicine, Faculty of Medicine, University of Oslo, Norway. 58)Faculty of Medicine, University of Iceland, Reykjavik, Iceland 59)Lund University Diabetes Centre, Department of Clinical Sciences, Lund University, Skåne University Hospital, SE-20502 Malmö, Sweden. 60)Department of Endocrinology, Abdominal Centre, Helsinki University Hospital, Helsinki, Finland. 61)Folkhalsan Research Center, Helsinki, Finland. 62)Diabetes Unit, Massachusetts General Hospital, Boston, USA. 63)Department of Clinical Sciences, Lund University, Malmö, Sweden. 64)Department of Nutrition, Harvard School of Public Health, Boston, MA, USA. 65)Oxford Centre for Diabetes, Endocrinology and Metabolism, Radcliffe Department of Medicine, University of Oxford, Oxford, UK. 66)Wellcome Centre for Human Genetics, Nuffield Department of Medicine, University of Oxford, Oxford, UK. 67)Program in Medical and Population Genetics, Broad Institute, Boston, MA, USA. 68)Bristol NIHR Biomedical Research Centre, Bristol, UK. 69)Centre for Genetics and Genomics Versus Arthritis, Centre for Musculoskeletal Research, Division of Musculoskeletal and Dermatological Sciences, University of Manchester, Manchester, UK. $\phi$ )Current address: Genentech, 1 DNA Way, South San Francisco, CA, USA. *)These authors contributed equally to this work. $\dagger$ )These authors supervised this work. 

medRxiv preprint doi: https://doi.org/10.1101/2021.10.11.21264235; this version posted October $14,2021$. The copyright holder for this
preprint (which was not certified by peer review) is the author/funder, who has granted medRxiv a license to display the preprint in perpetuity.

It is made available under a CC-BY 4.0 International license .

\begin{abstract}
Gestational diabetes mellitus (GDM) is associated with increased risk of pregnancy complications and adverse perinatal outcomes. GDM often reoccurs and is associated with increased risk of subsequent diagnosis of type 2 diabetes (T2D). To improve our understanding of the aetiological factors and molecular processes driving the occurrence of GDM, including the extent to which these overlap with T2D pathophysiology, the GENetics of Diabetes In Pregnancy (GenDIP) Consortium assembled genome-wide association studies (GWAS) of diverse ancestry in a total of 5,485 women with GDM and 347,856 without GDM. Through trans-ancestry meta-analysis, we identified five loci with genome-wide significant association $\left(p<5 \times 10^{-8}\right)$ with GDM, mapping to/near MTNR1B $\left(p=4.3 \times 10^{-54}\right)$, TCF7L2 $\left(p=4.0 \times 10^{-}\right.$ $\left.{ }^{16}\right), \operatorname{CDKAL1}\left(p=1.6 \times 10^{-14}\right), C D K N 2 A-C D K N 2 B\left(p=4.1 \times 10^{-9}\right)$ and HKDC1 $\left(p=2.9 \times 10^{-8}\right)$. Multiple lines of evidence pointed to genetic contributions to the shared pathophysiology of GDM and T2D: (i) four of the five GDM loci (not HKDC1) have been previously reported at genome-wide significance for T2D; (ii) significant enrichment for associations with GDM at previously reported T2D loci; (iii) strong genetic correlation between GDM and T2D; and (iv) enrichment of GDM associations mapping to genomic annotations in diabetes-relevant tissues and transcription factor binding sites. Mendelian randomisation analyses demonstrated significant causal association ( $5 \%$ false discovery rate) of higher body mass index on increased GDM risk. Our results provide support for the hypothesis that GDM and T2D are part of the same underlying pathology but that, as exemplified by the HKDC1 locus, there are genetic determinants of GDM that are specific to glucose regulation in pregnancy.
\end{abstract}


medRxiv preprint doi: https://doi.org/10.1101/2021.10.11.21264235; this version posted October 14, 2021. The copyright holder for this preprint (which was not certified by peer review) is the author/funder, who has granted medRxiv a license to display the preprint in perpetuity.

It is made available under a CC-BY 4.0 International license.

Gestational diabetes mellitus (GDM), defined as hyperglycaemia with onset or first recognition during pregnancy, is associated with increased risk of pregnancy complications and adverse perinatal outcomes, including pre-eclampsia, stillbirth, large for gestational age, neonatal hypoglycaemia, preterm birth, low Apgar scores and admission to neonatal intensive care $^{1-4}$. Whilst hyperglycaemia commonly resolves postpartum, GDM often reoccurs ${ }^{5}$ and is associated with subsequent diagnosis of type 2 diabetes (T2D) and coronary heart disease $\mathrm{e}^{6,7}$. Although the global prevalence of GDM is increasing, it varies according to population characteristics (such as maternal age, ancestry and obesity rates) and the criteria used for screening and diagnosis ${ }^{8}$.

GDM and T2D share both genetic and non-genetic risk factors, including obesity, poor diet and sedentary lifestyle ${ }^{9,10}$. Family studies have demonstrated that women with GDM have $30.1 \%$ probability of having at least one parent with T2D, compared to just $13.2 \%$ for pregnant women with normal glucose tolerance ${ }^{11}$. Furthermore, women with a history of GDM appear to have a nearly 10 -fold higher risk of developing T2D than those with a normo-glycaemic pregnancy ${ }^{7}$. Taken together, these observations support the hypothesis that the two diseases are part of the same underlying pathology, with pregnancy potentially acting as a stress test that reveals women at increased risk of GDM and/or T2 $\mathrm{D}^{12,13}$.

There have been considerable advances in our understanding of the genetic contribution to T2D through large-scale genome-wide association studies (GWAS) across diverse populations ${ }^{14-17}$. In contrast, despite the observed familial clustering of $\mathrm{GDM}^{18}$, most genetic association studies of the disease have focussed on evaluating the impact of previously reported loci for T2D and glycaemic traits in modest sample sizes ${ }^{19}$. The most comprehensive systematic review of genetic susceptibility to GDM (from 23 studies) revealed association with T2D risk variants from seven loci, of which six are related to insulin secretion and one to insulin resistance ${ }^{20}$. A genetic risk score (GRS) of risk variants across 34 loci associated with T2D and/or fasting glucose was significantly associated with GDM and improved predictive power over a model including only clinical variables ${ }^{21}$. Variants associated with both insulin secretion and insulin resistance have also been used to construct an aggregated GRS that was shown to predict GDM risk, with and without adjustment for body mass index (BMI), maternal age, and gestational age, although this score was not compared with established clinical predictors ${ }^{22}$. To date, the largest GWAS of GDM has been undertaken in women from a Korean population, including 468 cases and 1,242 non-diabetic controls in the discovery stage, with an additional 931 cases and 783 non-diabetic controls in the follow-up stage ${ }^{23}$. Two loci were associated with GDM at genome-wide significance $\left(p<5 \times 10^{-8}\right)$, mapping near MTNR1B and CDKAL1, both of which have also been previously implicated in T2D risk.

To gain novel insight into the genetic architecture of GDM, the GENetics of Diabetes In Pregnancy (GenDIP) Consortium assembled GWAS of diverse ancestry in a total of 5,485 women with GDM and 347,856 women without GDM: the effective sample size was $72.2 \%$ European, 13.4\% East Asian, 9.9\% South Asian, 2.8\% Hispanic/Latino and 1.7\% African (Tables S1 and S2). To maximise sample size, we used a phenotype definition that makes best use of the information available in each study, including data from health records, oral glucose tolerance tests and self-report (Table S1). Each GWAS was imputed to reference panels from the 1000 Genomes Project ${ }^{24}$, Haplotype Reference Consortium ${ }^{25}$, or population-specific whole-genome sequence data (Table S3). Within each GWAS, GDM association summary 
medRxiv preprint doi: https://doi.org/10.1101/2021.10.11.21264235; this version posted October 14, 2021. The copyright holder for this preprint (which was not certified by peer review) is the author/funder, who has granted medRxiv a license to display the preprint in perpetuity.

It is made available under a CC-BY 4.0 International license .

statistics were derived for all single nucleotide variants (SNVs) passing quality control after appropriate adjustment to account for population structure (Supplementary Materials and Methods, Table S3). With these resources, we aimed to improve our understanding of the aetiological factors and molecular processes driving the occurrence of GDM, including the extent to which these overlap with T2D pathophysiology, and investigate the effects of potential causal metabolic risk factors on the disease through Mendelian randomisation (MR).

We began by aggregating GDM association summary statistics across GWAS through transancestry meta-analysis. The most powerful methods allow for potential allelic effect heterogeneity on disease between ancestry groups that cannot be accommodated in a fixedeffects model ${ }^{26}$. Our primary analysis used MR-MEGA ${ }^{27}$, which models heterogeneity between GWAS by including axes of genetic variation that represent ancestry as covariates in a meta-regression model. We considered three axes of genetic variation that separated the five ancestry groups, but which also revealed finer-scale genetic differences between GWAS of the same ancestry (Figure S1). We also conducted trans-ancestry and ancestry-specific fixed-effects meta-analyses. We identified five loci at genome-wide significance in the transancestry meta-regression (Table 1, Figures S2 and S3), including the previously reported associations from GDM GWAS at MTNR1B ( $r$ 10830963, $p=4.3 \times 10^{-54}$ ) and CDKAL1 (rs9348441, $p=1.6 \times 10^{-14}$ ). The remaining three loci for GDM mapped to/near TCF7L2 (rs7903146, $\left.p=4.0 \times 10^{-16}\right), C D K N 2 A-C D K N 2 B\left(r s 10811662, p=4.1 \times 10^{-9}\right)$ and $H K D C 1$ ( $\left.r s 9663238, p=2.9 \times 10^{-8}\right)$. Through approximate conditional analyses, conducted using ancestry-matched linkage disequilibrium (LD) reference panels for each GWAS (Supplementary Materials and Methods), we observed no evidence for multiple distinct association signals at genome-wide significance at any of the five GDM loci (Figure S4).

We next sought to investigate the impact of differences in ancestry and phenotype definition between GWAS on heterogeneity in allelic effects at GDM loci. To do this, we extended the MR-MEGA meta-regression model to include an additional covariate to represent whether GDM status in the study was confirmed via "a universal blood-based test" (Supplementary Materials and Methods, Table S1). Here, we use this term to refer to a blood-based test that was applied to all participants, including a diagnostic oral glucose tolerance test (OGTT) or a screening glucose challenge or fasting glucose test, in contrast to clinician decision, risk factor screening, or a lack of clarity on what basis women did or did not have a diagnostic OGTT. This model enables partitioning of heterogeneity into three components (Table 2). The first component captures heterogeneity that is correlated with genetic ancestry (that can be explained by the three axes of genetic variation), which can occur because of differences in the structure of LD between ancestry groups or interactions with lifestyle factors that vary across populations. The second component measures heterogeneity that can be explained by the use of a universal blood-based test to screen for or diagnose GDM. The final component reflects residual heterogeneity due to study design that cannot be explained by the first two components. The greatest evidence of ancestry-correlated heterogeneity (after accounting for the use of a universal blood-based test) was observed at the CDKAL1 locus ( $p_{\text {HET }}=3.4 \times 10^{-}$ $\left.{ }^{5}\right)$, where the lead SNV demonstrated stronger 
Table 1. Loci attaining genome-wide significant $\left(p<5 \times 10^{-8}\right)$ evidence of association with GDM in trans-ancestry meta-regression (MR-MEGA) of 5,485 cases and 347,856 controls.

\begin{tabular}{|c|c|c|c|c|c|c|c|}
\hline \multirow[t]{2}{*}{ Locus } & \multirow[t]{2}{*}{ Lead SNV } & \multirow[t]{2}{*}{ Chr } & \multirow{2}{*}{$\begin{array}{l}\text { Position } \\
\text { (bp, b37) }\end{array}$} & \multicolumn{2}{|c|}{ Alleles } & \multirow{2}{*}{$\begin{array}{l}\text { MR-MEGA } \\
p \text {-value }\end{array}$} & \multirow{2}{*}{$\begin{array}{l}\text { Fixed-effects } \\
\text { OR }(95 \% \mathrm{Cl}) \\
\end{array}$} \\
\hline & & & & Risk & Other & & \\
\hline MTNR1B & rs10830963 & 11 & $92,708,710$ & $G$ & $\mathrm{C}$ & $4.3 \times 10^{-54}$ & $1.41(1.35-1.47)$ \\
\hline TCF7L2 & rs7903146 & 10 & $114,758,349$ & $\mathrm{~T}$ & $\mathrm{C}$ & $4.0 \times 10^{-16}$ & $1.22(1.16-1.27)$ \\
\hline CDKAL1 & rs9348441 & 6 & $20,680,678$ & A & $\mathrm{T}$ & $1.6 \times 10^{-14}$ & $1.13(1.08-1.18)$ \\
\hline$C D K N 2 A-C D K N 2 B$ & rs10811662 & 9 & $22,134,253$ & G & A & $4.1 \times 10^{-9}$ & $1.14(1.09-1.20)$ \\
\hline$H K D C 1$ & rs9663238 & 10 & $70,983,629$ & G & A & $2.9 \times 10^{-8}$ & 1.14 (1.09-1.19) \\
\hline
\end{tabular}

Chr: chromosome. OR: odds-ratio. Cl: confidence interval.

Table 2. Source of heterogeneity in allelic effects on GDM between GWAS for lead SNVs derived from meta-regression of 5,485 cases and 347,856 controls.

\begin{tabular}{|l|l|l|l|l|}
\hline \multirow{2}{*}{ Locus } & \multirow{2}{*}{ Lead SNV } & Heterogeneity source (p-value) & \multicolumn{2}{l|}{} \\
\cline { 3 - 5 } & & Ancestry & Universal blood-based test & 0.67 \\
\hline MTNR1B & rs10830963 & 0.14 & 0.41 & 0.089 \\
\hline TCF7L2 & rs7903146 & 0.25 & 0.83 & 0.15 \\
\hline CDKAL1 & rs9348441 & $3.4 \times 10^{-5}$ & 0.28 & 0.26 \\
\hline CDKN2A-CDKN2B & rs10811662 & 0.0022 & 0.45 & $5.4 \times 10^{-5}$ \\
\hline HKDC1 & rs9663238 & 0.19 & 0.33 & \\
\hline
\end{tabular}


medRxiv preprint doi: https://doi.org/10.1101/2021.10.11.21264235; this version posted October 14, 2021. The copyright holder for this preprint (which was not certified by peer review) is the author/funder, who has granted medRxiv a license to display the preprint in perpetuity.

It is made available under a CC-BY 4.0 International license .

effects on GDM in GWAS of East Asian ancestry than in other populations, despite the risk allele being common in all ancestry groups (Figure S5, Table S4). A similar pattern of ancestrycorrelated heterogeneity in allelic effects on T2D has been reported at the CDKAL1 locus ${ }^{16}$. Weaker evidence of ancestry-correlated heterogeneity was observed at the CDKN2A-CDKN2B locus ( $p_{\text {HET }}=0.0022$ ), where there were marked differences in the effects on GDM of the lead SNV between GWAS undertaken in different ancestry groups (Figure S5, Table S4). In contrast, there was no evidence of heterogeneity due to phenotype definition for any lead SNV, suggesting that differences in allelic effects between GWAS are more likely due to factors related to genetic ancestry than the use of a blood-based test in all women to screen for or diagnose GDM.

(a)

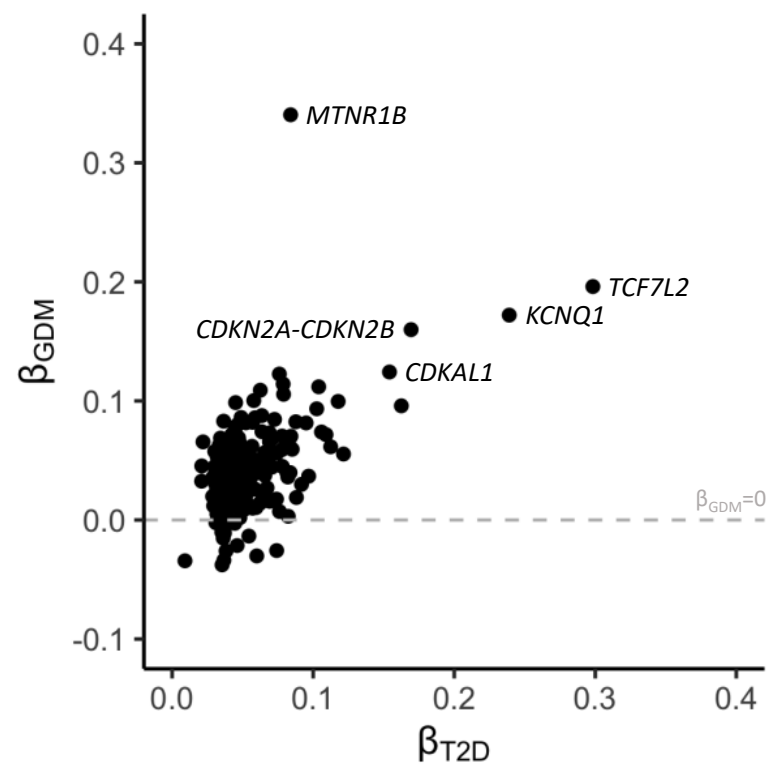

(b)

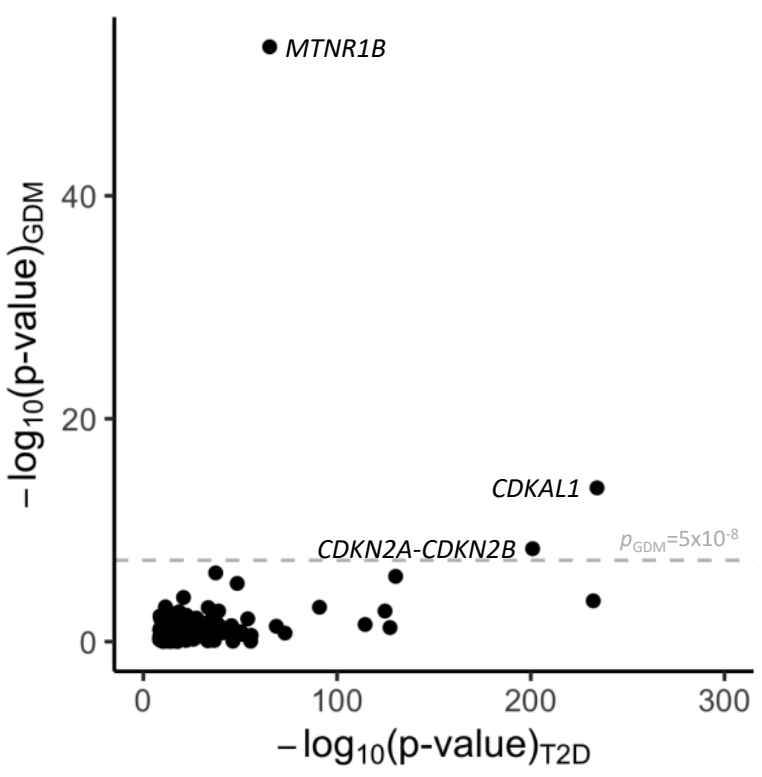

Figure 1. Correlation between GDM and T2D association summary statistics for lead SNVs at previously reported loci for T2D susceptibility. Association summary statistics for GDM were obtained from trans-ancestry GWAS meta-analyses of 5,485 cases and 347,856 controls. Association summary statistics for T2D were obtained from trans-ancestry GWAS meta-analyses of 180,834 cases and 1,159,055 controls from the DIAMANTE Consortium. (a) Allelic effect sizes (log-ORs) for each disease, aligned to the T2D risk allele, from fixed-effects meta-analysis. The grey line represents log-OR of zero for GDM. (b) Association evidence ( $\log 10 \mathrm{p}$-values) for each disease from meta-regression. The grey line represents genome-wide significance $(p<5 \times 10-8)$ for GDM. The lead SNV at the TCF7L2 locus has been removed for ease of presentation (Table S4).

Of the five GDM loci identified at genome-wide significance in the trans-ancestry metaregression, four have been previously implicated in T2D susceptibility: MTNR1B, TCF7L2, CDKAL1 and CDKN2A-CDKN2B. In fact, in previously reported trans-ancestry GWAS metaanalyses of 180,834 T2D cases and 1,159,055 controls from the DIAMANTE Consortium ${ }^{16}$, the lead T2D SNV is the same as we report for GDM at MTNR1B, TCF7L2 and CDKAL1, and is in strong linkage disequilibrium (LD) at the CDKN2A-CDKN2B locus ( $r$ 10811661, $r^{2}=0.91$ across diverse populations in the 1000 Genomes Project ${ }^{24}$ ). To further investigate the genetic correlation between the two diseases, we extracted GDM association summary statistics from 
medRxiv preprint doi: https://doi.org/10.1101/2021.10.11.21264235; this version posted October $14,2021$. The copyright holder for this preprint (which was not certified by peer review) is the author/funder, who has granted medRxiv a license to display the preprint in perpetuity.

It is made available under a CC-BY 4.0 International license .

our trans-ancestry meta-analysis for lead SNVs at 222 previously reported loci for T2D from the DIAMANTE Consortium ${ }^{16}$ (Figure 1, Table S5). We observed a strong positive correlation in log-ORs for the T2D risk allele between the two diseases: Pearson $r=0.573\left(p<2.2 \times 10^{-16}\right)$. There was also a highly significant enrichment of GDM associations at T2D loci (50 of 222 lead SNVs with $p<0.05$ and same direction of effect, binomial test $\left.p<2.2 \times 10^{-16}\right)$, indicating that they would be discovered at genome-wide significance with larger effective sample sizes. Indeed, after excluding the four overlapping GDM-T2D loci (Supplementary Materials and Methods), a weighted genetic risk score of lead T2D SNVs was significantly associated with GDM $\left(p=9.7 \times 10^{-123}\right.$, pseudo- $\left.R^{2}=2.86 \%\right)$. Extending our analyses, genome-wide, using LD-score regression, we observed strong genetic correlation between GDM and T2D: $r_{G}(95 \% \mathrm{Cl}): 0.744$ $(0.052,1.437)$. Weaker genetic correlations between GDM and other glycaemic traits were also observed (Table 3, Table S6). These results are consistent with sharing of genetic determinants of GDM and T2D, although we acknowledge that LD score regression has limited statistical power because of the relatively small GDM sample size, and we note that the correlation from LD-score regression is not bound by -1 to 1 , particularly when power is low.

Table 3. Genetic correlation from LD-score regression of GDM with T2D and glycaemic traits.

\begin{tabular}{|l|l|}
\hline Trait & Genetic correlation $\mathbf{r}_{\mathbf{G}}(\mathbf{9 5} \% \mathbf{C l})^{\mathbf{a}}$ \\
\hline T2D & $0.744(0.052,1.437)$ \\
\hline Fasting glucose & $0.218(-0.211,0.648)$ \\
\hline Fasting insulin & $0.410(-0.114,0.934)$ \\
\hline Fasting proinsulin & $0.336(-0.321,0.993)$ \\
\hline 2hr glucose (adjusted for BMI) & $0.444(-0.371,1.260)$ \\
\hline HbA1c & $0.387(-0.218,0.991)$ \\
\hline HOMA-B & $-0.005(-0.551,0.541)$ \\
\hline HOMA-IR & $0.236(-0.382,0.854)$ \\
\hline
\end{tabular}

$\mathrm{Cl}$ : Confidence Interval. T2D: type 2 diabetes. HbA1c: glycated haemoglobin. BMI: body mass index. HOMA-B: homeostasis model assessment of $\beta$-cell activity; HOMA-IR: homeostasis model assessment of insulin resistance. a Genetic correlation obtained from LD-score regression is not bound by -1 to 1 and estimates can therefore be found outside these limits due to high imprecision caused by factors such as low sample size in the association summary statistics used.

The most obvious difference in allelic effect sizes between GDM and T2D was observed at the MTNR1B locus (Figure 1). The lead SNV, rs10830963, is the same for both diseases, but the allelic effect on GDM is substantially greater than on T2D: OR (95\% Cl) for GDM is 1.41 (1.351.47) and for T2D is just 1.09 (1.08-1.10). The MTNR1B lead SNV is associated, at genomewide significance, with fasting glycaemic traits in non-diabetic individuals from the MetaAnalysis of Glucose and Insulin-related traits Consortium (MAGIC) Investigators ${ }^{28,29}$. The GDM risk allele at the lead SNV is also associated with higher fasting plasma glucose and 1-hour plasma glucose in pregnant women from the Hyperglycemia and Adverse Pregnancy Outcomes (HAPO) Study ${ }^{30}$. This SNV also has the strongest association of the maternal glucose-raising allele with higher offspring birth weight in women from the Early Growth Genetics Consortium $^{31}$, in line with the known effects of maternal hyperglycaemia on fetal growth. In non-diabetic individuals from the MAGIC Investigators ${ }^{32}$, the MTNR1B lead SNV has a much larger impact on fasting glucose than those at TCF7L2, CDKAL1 and CDKN2A- 
medRxiv preprint doi: https://doi.org/10.1101/2021.10.11.21264235; this version posted October 14, 2021. The copyright holder for this preprint (which was not certified by peer review) is the author/funder, who has granted medRxiv a license to display the preprint in perpetuity.

It is made available under a CC-BY 4.0 International license .

CDKN2B ${ }^{33}$ (Table S7). Therefore, the difference in allelic effect sizes between GDM and T2D at MTNR1B may reflect the fact that thresholds of fasting plasma glucose used to diagnose GDM are lower than those used to diagnose T2D, meaning that a larger proportion of GDM than T2D cases will have higher fasting glucose that is regulated within the normal range.

To gain insight into the molecular processes and tissues through which GDM association signals are mediated, genome-wide, we then undertook fGWAS enrichment analyses within three categories of functional and regulatory annotations: (i) genic regions ${ }^{34}$; (ii) chromatin immuno-precipitation sequence (ChIP-seq) binding sites for 165 transcription factors ${ }^{35,36}$; and (iii) 13 unique and recurrent chromatin states in four diabetes-relevant tissues (pancreatic islets, liver, adipose, and skeletal muscle) ${ }^{37}$. We observed significant joint enrichment $(p<0.05)$ for GDM associations mapping to protein coding exons, binding sites for FOXA2, NFE2 and TFAP2, and chromatin states in adipose tissue and skeletal muscle that mark enhancers and transcribed regions (Table S8). FOXA2 is a pioneer factor involved in pancreatic and hepatic development, and T2D association signals have been previously reported to be enriched for FOXA2 binding sites ${ }^{38}$. Skeletal muscle is the most prominent site of insulinmediated glucose uptake in humans, and enhancers in skeletal muscle have been reported to overlap association signals for metabolic disorders, including T2D, insulin resistance and obesity ${ }^{39}$. These enrichment analyses highlight molecular processes and tissues that are broadly consistent with those important in mediating T2D association signals ${ }^{16}$, although the involvement of pancreatic islets appears to be less prominent for GDM.

In contrast to the other GDM loci reported in this investigation, the lead SNV at the HKDC1 locus (rs9663238) demonstrates only weak statistical evidence of T2D association in previously reported trans-ancestry GWAS meta-analyses from the DIAMANTE Consortium ${ }^{16}$ ( $p=0.0083$, compared with $p<10^{-65}$ at the other four loci). GDM risk alleles at variants in strong LD (European ancestry $r^{2}>0.9$ ) with the lead SNV have been previously associated, at genomewide significance, with higher 2-hour plasma glucose (2HPG) in pregnant women in the HAPO Study and two replication studies of European ancestry ${ }^{30}$, as well as with higher birth weight of first child (likely via greater maternal glucose availability), higher own birth weight (fetal effect independent of the maternal effect on birth weight), and comparative height and body size at age 10 in UK Biobank ${ }^{40,41}$ (Table S9). In addition to demonstrating the association of the maternal SNVs at this locus with GDM in the current study, we observed that $99 \%$ credible set variants are lead SNVs for HKDC1 expression quantitative trait loci in a range of tissues in the GTEx Project ${ }^{42}$, including visceral adipose, subcutaneous adipose and pancreas (Supplementary Materials and Methods, Table S10). HKDC1 (Hexokinase Domain Containing 1) catalyzes the phosphorylation of hexose to hexose 6-phosphate and is involved in glucose homeostasis and hepatic lipid accumulation. Haplotypes of variants associated with 2HPG in pregnancy disrupt regulatory element activity and reduce HKDC1 expression across diverse tissues (including metabolically relevant liver stellate cells and pancreatic islet beta cells), which has been demonstrated to reduce hexokinase activity in multiple cellular models $\mathrm{s}^{43}$. Knockout of hepatic HKDC1 in pregnant mice has also been demonstrated to significantly impair glucose tolerance, highlighting the importance of liver HKDC1 on glucose metabolism during pregnancy ${ }^{44}$. Taken together, the evidence from our study and others suggests a more important role for HKDC1 in glucose metabolism during pregnancy than outside of pregnancy, in addition to independent maternal and offspring effects on early growth, and highlights that 
medRxiv preprint doi: https://doi.org/10.1101/2021.10.11.21264235; this version posted October 14,2021 . The copyright holder for this preprint (which was not certified by peer review) is the author/funder, who has granted medRxiv a license to display the preprint in perpetuity

It is made available under a CC-BY 4.0 International license .

while GDM shares many similarities with T2D, there are differences in at least one underlying pathway.

Finally, we used two-sample MR to investigate causal effects on GDM of 282 metabolic measures and risk factors available in the MR-Base GWAS catalogue (www.mrbase.org) ${ }^{45}$, including metabolites, anthropometric measures, hormones, immune system phenotypes, kidney traits and metals (Supplementary Materials and Methods, Table S11). We did not consider glycaemic traits (including $\mathrm{HbA1c}$ ) because they are used to define GDM status. For each metabolic measure, we selected independent SNVs attaining genome-wide significance with the trait as instrumental variables. For each SNV, we extracted association summary statistics for GDM from the European ancestry-specific meta-analysis because we assessed independence of genetic instruments using LD from European ancestry haplotypes from the 1000 Genomes Project ${ }^{24}$. Of the 282 exposures considered, only BMI demonstrated significant evidence for a causal effect on GDM risk at a false discovery rate of 5\% (Table S11). The estimated causal effect of higher BMI on higher GDM risk was directionally consistent across multiple MR models (Figure 2). The causal relationship of BMI with GDM is consistent with its effect on $\mathrm{T}^{2} \mathrm{D}^{46}$.
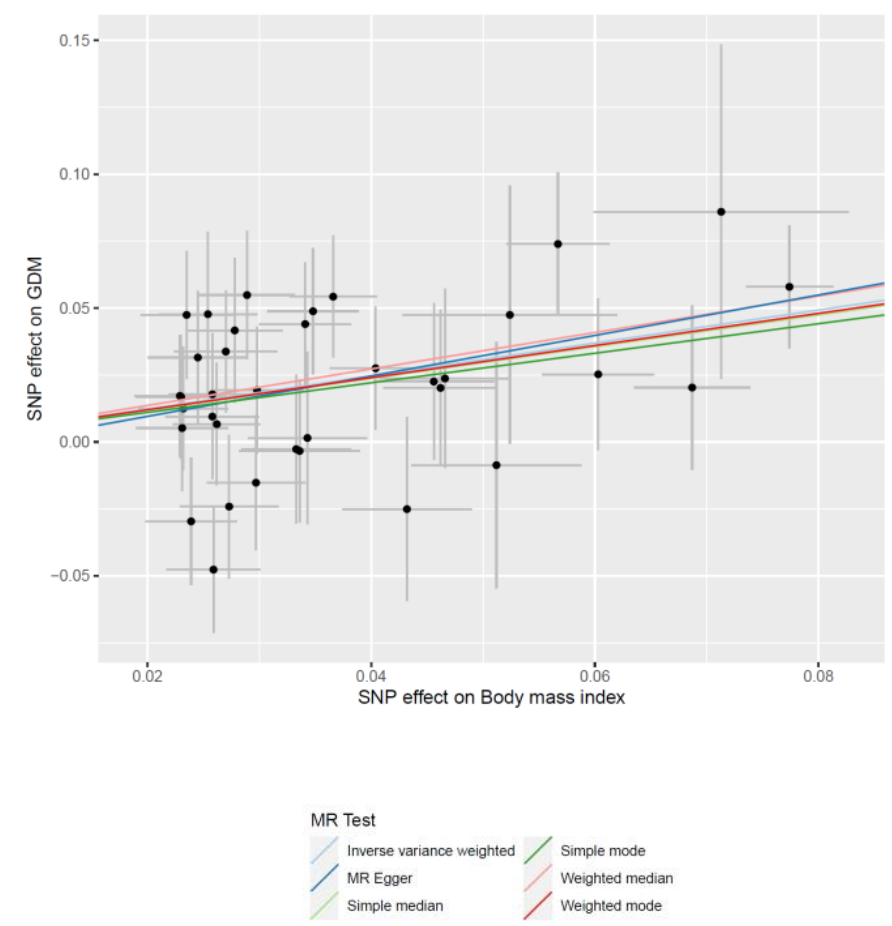

Figure 2. Effects of BMI on GDM from MR analyses. Each point corresponds to an independent SNV (genetic instrument), plotted according to the effect on BMI (on the $x$-axis) and the effect on GDM (log-OR, on the $y$-axis). Horizontal and vertical bars represent the standard errors of effect estimates. The coloured regression lines represent the effect of BMI on GDM from six MR models.

In conclusion, we have conducted the largest and most ancestrally diverse GWAS metaanalysis for GDM, where we identified associations mapping to MTNR1B, TCF7L2, CDKAL1, $C D K N 2 A-C D K N 2 B$ and $H K D C 1$. Our results demonstrated strong correlation in the effects of previously reported associations for T2D and those observed for GDM, and highlighted 
medRxiv preprint doi: https://doi.org/10.1101/2021.10.11.21264235; this version posted October 14, 2021. The copyright holder for this preprint (which was not certified by peer review) is the author/funder, who has granted medRxiv a license to display the preprint in It is made available under a CC-BY 4.0 International license .

overlapping molecular mechanisms and tissues that mediate associations for both diseases. In contrast, variation at the HKDC1 locus is not strongly associated with T2D, but instead plays a more important role in glucose metabolism during pregnancy than outside of pregnancy. The genetic diversity of GWAS contributing to our meta-analysis enabled identification of ancestry-correlated heterogeneity in allelic effects on GDM at two loci. Such heterogeneity could reflect variable impact of different pathophysiology driving glycaemic dysregulation in pregnancy between ancestries and emphasizes the need for increased sample sizes in underrepresented population groups. In contrast, results were consistent between GWAS in which all women had a universal blood-based test and those that did not, suggesting little impact from misclassification due to selective use of diagnostic tests only in those deemed to be at high-risk. Finally, MR analyses revealed a significant causal effect of higher BMI on GDM risk, consistent with the causal association observed with T2D. Taken together, these results provide further support for the hypothesis that T2D and GDM are part of the same underlying pathology. However, they also highlight there are pathways to GDM that impact on glucose regulation only in pregnancy, and that additional GDM-specific associations will be revealed through GWAS in larger sample sizes. 
medRxiv preprint doi: https://doi.org/10.1101/2021.10.11.21264235; this version posted October 14,2021 . The copyright holder for this preprint (which was not certified by peer review) is the author/funder, who has granted medRxiv a license to display the preprint in perpetuity.

It is made available under a CC-BY 4.0 International license .

\section{ACKNOWLEDGEMENTS}

ALSPAC. Core funding for ALSPAC is provided by the UK Medical Research Council and Wellcome (217065/Z/19/) and the University of Bristol. Genotyping of the ALSPAC maternal samples was funded by Wellcome (WT088806) and the offspring samples were genotyped by Sample Logistics and Genotyping Facilities at the Wellcome Sanger Institute and LabCorp (Laboratory Corporation of America) using support from 23andMe. A comprehensive list of grants funding is available on the ALSPAC website (http://www.bristol.ac.uk/alspac/external/documents/grant-acknowledgements.pdf). We are extremely grateful to all the families who took part in ALSPAC, the midwives for their help in recruiting them, and the whole ALSPAC team, which includes interviewers, computer and laboratory technicians, clerical workers, research scientists, volunteers, managers, receptionists and nurses.

AM. We thank the participants of the ANDIS-MDC study. The study is supported by Swedish Research Council (project grant 521-2010-3490 and infrastructure grants 2010-5983, 20125538, and 2014-6395). The study is supported by Crafoord foundation (project grant 20200891) and Hjärt-Lungfonden (project grant: 20180522).

BIB. Born in Bradford (BiB) data used in this research was funded by Wellcome (WT101597MA), a joint grant from the UK Medical Research Council (MRC) and UK Economic and Social Science Research Council (ESRC) (MR/N024397/1), the British Heart Foundation (CS/16/4/32482) and the National Institute for Health Research (NIHR) under its Collaboration for Applied Health Research and Care (CLAHRC) for Yorkshire and Humber and the Clinical Research Network (CRN). Born in Bradford is only possible because of the enthusiasm and commitment of the Children and Parents in BiB. We are grateful to all the participants, teachers, school staff, health professionals and researchers who have made Born in Bradford happen.

BOTNIA. The Botnia Study (L.G., T.T.) have been financially supported by grants from Folkhälsan Research Foundation, the Sigrid Juselius Foundation, The Academy of Finland (grants no. 263401, 267882, 312063, 336822 to LG; 312072 and 336826 to TT), University of Helsinki, Nordic Center of Excellence in Disease Genetics, EU (EXGENESIS), MOSAIC FP7600914, Ollqvist Foundation, Swedish Cultural Foundation in Finland, Finnish Diabetes Research Foundation, Foundation for Life and Health in Finland, Signe and Ane Gyllenberg Foundation, Finnish Medical Society, Paavo Nurmi Foundation, State Research Funding via the Helsinki University Hospital, Perklén Foundation, Närpes Health Care Foundation and Ahokas Foundation. The study has also been supported by the Ministry of Education in Finland, Municipal Heath Care Center and Hospital in Jakobstad and Health Care Centers in Vasa, Närpes and Korsholm. The research leading to these results has received funding from the European Research Council under the European Union's Seventh Framework Programme (FP7/2007-2013) / ERC grant agreement $n^{\circ} 269045$. The study is also supported by Crafoord foundation (project grant 20200891) and Hjärt-Lungfonden (project grant: 20180522) (RBP). The skillful assistance of the Botnia Study Group is gratefully acknowledged.

DECODE. We thank the women who have participated in the deCODE study. 
medRxiv preprint doi: https://doi.org/10.1101/2021.10.11.21264235; this version posted October 14, 2021. The copyright holder for this preprint (which was not certified by peer review) is the author/funder, who has granted medRxiv a license to display the preprint in perpetuity.

It is made available under a CC-BY 4.0 International license .

EGCUT. This study was funded by the European Union through the European Regional Development Fund (Project No. 2014-2020.4.01.15-0012 and Project No. 2014-2020.4.01.160125), by the European Union through Horizon 2020 research and innovation programme under grant agreement No 101017802 and 810645 and by the Estonian Research Council grants PUT (PRG687, PRG1291). Data analyses were carried out in part in the HighPerformance Computing Center of University of Tartu. We thank participants and support staff of Estonian Biobank.

FINNGEDI. The EPX-GDM study has been supported by the French government, managed by the National Research Agency (ANR) under the Future Investment Program (PIA) with the references ANR-10-LABX-0046 (European Genomic Institute for Diabetes [E.G.I.D]) and ANR10-EQPX-07-01 (LIGAN-PM). This work was also supported by the ANR-16-CE17-0017-01, by the Fondation Francophone pour la Recherche sur le Diabète (FFRD) that is sponsored by the Fédération Française des Diabétiques (FFD), Abbott, AstraZeneca, Eli Lilly, Merck Sharp \& Dohme (MSD) and Novo Nordisk, and by the National Center for Precision Diabetic Medicine - PreciDIAB, which is jointly supported by the French National Agency for Research (ANR-18IBHU-0001), by the European Union (FEDER), by the Hauts-de-France Regional Council and by the European Metropolis of Lille (MEL). The FinnGeDi study was supported by: Academy of Finland, Diabetes Research Foundation, Foundation for Pediatric Research, Juho Vainio Foundation, Novo Nordisk Foundation, Signe and Ane Gyllenberg Foundation, Sigrid Jusélius Foundation, Yrjö Jahnsson Foundation for Pediatric Research, Finnish DiabetesMedical Foundation, Research Funds of Oulu University Hospital (state grants), Research Foundation, Novo Nordisk Foundation, funds of Helsinki University Hospital (state grants), Medical Research Center Oulu and National Institute for Health and Welfare (Finland).

ERF. We are grateful to all participants and their relatives, to general practitioners and neurologists for their contributions, to P. Veraart for her help in genealogy, to Jeannette Vergeer for the supervision of the laboratory work, and to P. Snijders for his help in data collection. The ERF study was supported by grants from the Netherlands Organisation for Scientific Research (Pionier, 047.016.009, 047.017.043), Erasmus MC, and the Centre for Medical Systems Biology (CMSB; National Genomics Initiative). Ayse Demrkan was supported by NWO (VENI-91616165), WCRF-2017/1641 and H2020-SC1-2019-874739.

ESTGDM. This study was supported by the Estonian Research Council grants IUT20-43 and PRG712. We are grateful to Dr Anne Kirss and midwife Mrs Laura Lauren from Women's Clinic, Tartu University Hospital, for interviewing the participants and collecting the blood samples.

GEN3G. Gen3G has been supported by an American Diabetes Association accelerator award \#1-15-ACE-26 (M.F.H), Fonds de Recherche du Québec en Santé \#20697 (M.F.H); Canadian Institute of Health Research \#MOP 115071 (M.F.H), and Diabète Québec grants (P.P. and L.B.). Gen3G research team thanks all Gen3G participants.

GIFTS. This study was supported by Medical Research Council [Clinical Research Training Fellowship (G0800441)], the European Union (FP7 EU grant: 83599025) and the Diabetes Association of Bangladesh. The authors are indebted to all the participants from Dhaka (Bangladesh) and London (UK). 
medRxiv preprint doi: https://doi.org/10.1101/2021.10.11.21264235; this version posted October 14, 2021. The copyright holder for this preprint (which was not certified by peer review) is the author/funder, who has granted medRxiv a license to display the preprint in perpetuity.

It is made available under a CC-BY 4.0 International license .

HONGKONG. This study was supported by National Institutes of Health (NIH) grants HD34242, HD-34243, HG-004415, and CA-141688, Institutes of Health Research-INMD (Funding Reference Number 110791), and by the American Diabetes Association. The authors are indebted to the participants of the HAPO Study at Hong Kong.

NFBC Cohort 1966 31y follow-up study. We thank all cohort members and researchers who participated in the 31 yrs study. We also wish acknowledge the work of the NFBC project center. NFBC1966 received financial support from University of Oulu Grant no. 65354 and 24000692, Oulu University Hospital Grant no. 2/97, 8/97, and 24301140, Ministry of Health and Social Affairs Grant no. 23/251/97, 160/97, 190/97. National Institute for Health and Welfare, Helsinki Grant no. 54121, Regional Institute of Occupational Health, Oulu, Finland Grant no. 50621, 54231, 54121, Regional Institute of Occupational Health, Oulu, Finland Grant no. 50621, 54231 and ERDF European Regional Development Fund Grant no. 539/2010 A31592. The NFBC team is acknowledging the following Funding/Support: This work was supported by the European Union's Horizon 2020 research and innovation program under grant agreement No. 633595 (DynaHEALTH), and grant agreement No.733206 (LifeCycle) H2020-824989 EUCANCONNECT, H2020-873749 LongITools, H2020-848158 EarlyCause and the JPI HDHL, PREcisE project MR/S03658X/1, ZonMw the Netherlands no. P75416; the academy of Finland EGEA-project (285547).

NFBC Cohort 1966 46y follow-up study. We thank all cohort members and researchers who participated in the 46 yrs study. We also wish acknowledge the work of the NFBC project center. NFBC1966 received financial support from University of Oulu Grant no. 24000692, Oulu University Hospital Grant no. 24301140, ERDF European Regional Development Fund Grant no. 539/2010 A31592.

NFBC Cohort 1986. We thank all cohort members and researchers who have participated in the study. We also wish acknowledge the work of the NFBC project center.

NFBC1986 received financial support: EU QLG1-CT-2000-01643 (EUROBLCS) Grant no. E51560, NorFA Grant no. 731, 20056, 30167, USA / NIH 2000 G DF682 Grant no. 50945. . The NFBC team acknowledges the following funding/support: the European Union's Horizon 2020 research and innovation program under grant agreement No. 633595 (DynaHEALTH), and grant agreement No.733206 (LifeCycle) H2020-824989 EUCANCONNECT, H2020-873749 LonglTools, H2020-848158 EarlyCause and the JPI HDHL, PREcisE project, ZonMw the Netherlands no. P75416; the academy of Finland EGEA-project (285547).

PREDO. The PREDO study was supported by Academy of Finland, EVO research funding (A special Finnish state subsidy for health science research), Finnish Medical Foundation, Jane and Aatos Erkko Foundation, Päivikki and Sakari Sohlberg Foundation, University of Helsinki Research Funding, Jalmari ja Rauha Ahokas foundation, Yrjö Jahnsson foundation, Juho Vainio foundation.

SNUH. This work was supported by the Korea Health 21 R\&D Project, Korean Ministry of Health and Welfare (grant no. 00-PJ3-PG6-GN07-001). This study was supported by a grant from the Korea Health Technology R\&D Project through the Korea Health Industry Development Institute, funded by the Ministry of Health \& Welfare, Republic of Korea to S.H.K (grant number HI15C3131). 
medRxiv preprint doi: https://doi.org/10.1101/2021.10.11.21264235; this version posted October 14,2021 . The copyright holder for this preprint (which was not certified by peer review) is the author/funder, who has granted medRxiv a license to display the preprint in perpetuity.

It is made available under a CC-BY 4.0 International license .

STORK. The STORK study received additional funding from the Norwegian Diabetes Association, the Norwegian Odd Fellow Research Fund and Johan Selmer Kvanes' Endowment for Research in Diabetes.

STORKG. Acknowledge Hormone Laboratory, Oslo University Hospital for DNA-extraction.

UKBB. UK Biobank analyses were conducted using the UK Biobank resource under application 11867.

VIVA. Grants from the US National Institutes of Health (R01 HD034568, UH3 OD023286). Project Viva is thankful to all Project Viva participants for their participation to research over many years.

Individual author acknowledgements. D.A.L. is supported by the European Research Council (669545), US National Institute for Health (R01 DK10324), and British Heart Foundation (CH/F/20/90003). D.A.L. and M.C.B. work in a Unit supported by the University of Bristol and the UK Medical Research Council (MC_UU_00011/6) and are supported by a British Heart Foundation Accelerator Award (AA/18/7/34219). R.M.F. and R.N.B. were supported by Sir Henry Dale Fellowship (Wellcome and Royal Society grant: WT104150). R.M.F. is funded by a Wellcome Senior Research Fellowship (WT220390). G.H.M. has received funding from the South-Eastern Health Authority of Norway, the Norwegian Diabetes Association and Nils Normans Minnegave. G.H.M. is supported by the Norwegian Research Council (Post doctorial mobility research grant 287198).

M.C.B. was funded by a Medical Research Council (MRC) Skills Development Fellowship [MR/P014054/1] and a University of Bristol Vice-Chancellor's Fellowship.

The authors acknowledge the use of the University of Exeter High-Performance Computing (HPC) facility in carrying out this work.

Funders and others acknowledged here had no influence on the study design, data collection or interpretation of results. Views expressed are those of the authors and not necessarily any funder or other acknowledged here.

This research was funded in part, by Wellcome grants WT104150 and WT220390. A CC BY or equivalent licence is applied to the author accepted manuscript arising from this submission, in accordance with the grant's open access conditions.

\section{CONFLICTS OF INTEREST}

D.A.L. has received support from Roche Diagnostics and Medtronic Ltd for work unrelated to that presented here. M.I.M. has served on advisory panels for Pfizer, NovoNordisk and Zoe Global, has received honoraria from Merck, Pfizer, Novo Nordisk and Eli Lilly, and research funding from Abbvie, Astra Zeneca, Boehringer Ingelheim, Eli Lilly, Janssen, Merck, NovoNordisk, Pfizer, Roche, Sanofi Aventis, Servier, and Takeda. M.I.M. is now an employee 
medRxiv preprint doi: https://doi.org/10.1101/2021.10.11.21264235; this version posted October 14, 2021. The copyright holder for this preprint (which was not certified by peer review) is the author/funder, who has granted medRxiv a license to display the preprint in It is made available under a CC-BY 4.0 International license .

of Genentech and a holder of Roche stock. G.T., V.S., and K.S. are employees of deCODE genetics/Amgen, Inc.

\section{AUTHOR CONTRIBUTIONS}

Central analysis group: N.P., G-H..M., M.-C.B., T.F., J.P.C., R.M.F., D.A.L., A.P.M., R.M. Cohort analysis group: G.M., M.B., T.F., C.A., R.N.B., M.C., G.H., A.Heiskala, A.Joensuu, V.K., S.K., F.T.J.L., J.Liu, S.R.-S., G.T., S.H., R.B.P. Cohort sample collection, phenotyping, genotyping and additional analysis: T.A., J.A., B.B., A.B., F.D., A.D., P.F., K.H., H.H., S.H., A.Hussain, E.Kajantie, E.Keikkala, A.K., J.Lahti, T.L., S.M., C.S., A.T., E.T., R.U., M.V., P.M.V., R.B.P., R.M.F. Cohort PI: K.I.B., L.B., C.M.D., S.F., L.G., E.H., G.M.H., G.A.H., H.C.J., M.J., A.Jenum, H.L., O.M., E.O., K.P., P.P., R.B.P., E.Q., S.S., K.S., V.S., T.T., M.-F.H., P.W.F., M.I.M, C.M.L., D.A.L., A.P.M., R.M. Writing group: G.-H.M., M.-C.B., C.M.L., R.M.F., D.A.L., A.P.M., R.M. 
medRxiv preprint doi: https://doi.org/10.1101/2021.10.11.21264235; this version posted October 14,2021 . The copyright holder for this preprint (which was not certified by peer review) is the author/funder, who has granted medRxiv a license to display the preprint in perpetuity.

It is made available under a CC-BY 4.0 International license .

\section{REFERENCES}

1. Metzger, B. E. Hyperglycaemia and adverse pregnancy outcome (HAPO) study: Associations with maternal body mass index. BJOG An Int. J. Obstet. Gynaecol. 117, 575-584 (2010).

2. Farrar, D. et al. Association between hyperglycaemia and adverse perinatal outcomes in south Asian and white British women: Analysis of data from the Born in Bradford cohort. Lancet Diabetes Endocrinol. 3, 795-804 (2015).

3. Farrar, D. et al. Hyperglycaemia and risk of adverse perinatal outcomes: Systematic review and meta-analysis. BMJ (Online) vol. 354 (2016).

4. Stacey, T. et al. Gestational diabetes and the risk of late stillbirth: a case-control study from England, UK. BJOG An Int. J. Obstet. Gynaecol. 126, 973-982 (2019).

5. Kwak, S. H. et al. Subsequent pregnancy after gestational diabetes mellitus. Diabetes Care 31, 1867-1871 (2008).

6. Kramer, C. K., Campbell, S. \& Retnakaran, R. Gestational diabetes and the risk of cardiovascular disease in women: a systematic review and meta-analysis. Diabetologia vol. 62 905-914 (2019).

7. Vounzoulaki, E. et al. Progression to type 2 diabetes in women with a known history of gestational diabetes: Systematic review and meta-analysis. BMJ 369, (2020).

8. Farrar, D. Hyperglycemia in pregnancy: Prevalence, impact, and management challenges. Int. J. Womens. Health 8, 519-527 (2016).

9. American Diabetes Association. Gestational Diabetes Mellitus. Diabetes Care vol. 27 s88-s90 (2004).

10. Zhang, C. \& Ning, Y. Effect of dietary and lifestyle factors on the risk of gestational diabetes: Review of epidemiologic evidence. in American Journal of Clinical Nutrition vol. 94 (Am J Clin Nutr, 2011).

11. Jang, H. C., Min, H. K., Lee, H. K., Cho, N. H. \& Metzger, B. E. Short stature in Korean women: A contribution to the multifactorial predisposition to gestational diabetes mellitus. Diabetologia 41, 778-783 (1998).

12. Sattar, N. \& Greer, I. A. Pregnancy complications and maternal cardiovascular risk: Opportunities for intervention and screening? British Medical Journal vol. 325 157-160 (2002).

13. Rich-Edwards, J. W., Fraser, A., Lawlor, D. A. \& Catov, J. M. Pregnancy characteristics and women's future cardiovascular health: An underused opportunity to improve women's health? Epidemiol. Rev. 36, 57-70 (2014).

14. Vujkovic, M. et al. Discovery of 318 new risk loci for type 2 diabetes and related vascular outcomes among 1.4 million participants in a multi-ancestry meta-analysis. Nat. Genet. 52, 680-691 (2020).

15. Spracklen, C. N. et al. Identification of type 2 diabetes loci in 433,540 East Asian individuals. Nature 582, 240-245 (2020).

16. Mahajan, A. et al. Trans-ancestry genetic study of type 2 diabetes highlights the power of diverse populations for discovery and translation. medRxiv (2020).

17. Mahajan, A. et al. Fine-mapping type 2 diabetes loci to single-variant resolution using high-density imputation and islet-specific epigenome maps. Nat. Genet. 50, 1505-1513 (2018).

18. Watanabe, R. M. Inherited destiny? Genetics and gestational diabetes mellitus. Genome Medicine vol. 3 (2011). 
medRxiv preprint doi: https://doi.org/10.1101/2021.10.11.21264235; this version posted October 14,2021 . The copyright holder for this preprint (which was not certified by peer review) is the author/funder, who has granted medRxiv a license to display the preprint in perpetuity.

It is made available under a CC-BY 4.0 International license .

19. Powe, C. E. \& Kwak, S. H. Genetic Studies of Gestational Diabetes and Glucose Metabolism in Pregnancy. Current Diabetes Reports vol. 20 (2020).

20. Zhang, C. et al. Genetic variants and the risk of gestational diabetes mellitus: A systematic review. Hum. Reprod. Update 19, 376-390 (2013).

21. Kawai, V. K. et al. A genetic risk score that includes common type 2 diabetes risk variants is associated with gestational diabetes. Clin. Endocrinol. (Oxf). 87, 149-155 (2017).

22. Powe, C. E. et al. Genetic determinants of glycemic traits and the risk of gestational diabetes mellitus. Diabetes 67, 2703-2709 (2018).

23. Kwak, S. H. et al. A genome-wide association study of gestational diabetes mellitus in Korean women. Diabetes 61, 531-541 (2012).

24. Auton, A. et al. A global reference for human genetic variation. Nature vol. 526 68-74 (2015).

25. McCarthy, S. et al. A reference panel of 64,976 haplotypes for genotype imputation. Nat. Genet. 48, 1279-1283 (2016).

26. Gurdasani, D., Barroso, I., Zeggini, E. \& Sandhu, M. S. Genomics of disease risk in globally diverse populations. Nature Reviews Genetics vol. 20 520-535 (2019).

27. Mägi, R. et al. Trans-ethnic meta-regression of genome-wide association studies accounting for ancestry increases power for discovery and improves fine-mapping resolution. Hum. Mol. Genet. 26, 3639-3650 (2017).

28. Scott, R. A. et al. Large-scale association analyses identify new loci influencing glycemic traits and provide insight into the underlying biological pathways. Nat. Genet. 44, 9911005 (2012).

29. Chen, J. et al. The trans-ancestral genomic architecture of glycemic traits. Nat. Genet. 53, 840-860 (2021).

30. Hayes, M. G. et al. Identification of HKDC1 and BACE2 as genes influencing glycemic traits during pregnancy through genome-wide association studies. Diabetes 62, 32823291 (2013).

31. Beaumont, R. N. et al. Genome-wide association study of offspring birth weight in 86 577 women identifies five novel loci and highlights maternal genetic effects that are independent of fetal genetics. Hum. Mol. Genet. 27, 742-756 (2018).

32. Chen, J. et al. The Trans-Ancestral Genomic Architecture of Glycaemic Traits. Astrid van Hylckama Vlieg 14, 203 (2020).

33. Morris, A. P. et al. Large-scale association analysis provides insights into the genetic architecture and pathophysiology of type 2 diabetes. Nat. Genet. 44, 981-990 (2012).

34. Harrow, J. et al. GENCODE: The reference human genome annotation for the ENCODE project. Genome Res. 22, 1760-1774 (2012).

35. Dunham, l. et al. An integrated encyclopedia of DNA elements in the human genome. Nature 489, 57-74 (2012).

36. Pasquali, L. et al. Pancreatic islet enhancer clusters enriched in type 2 diabetes riskassociated variants. Nat. Genet. 46, 136-143 (2014).

37. Varshney, A. et al. Genetic regulatory signatures underlying islet gene expression and type 2 diabetes. Proc. Natl. Acad. Sci. U. S. A. 114, 2301-2306 (2017).

38. Gaulton, K. J. et al. Genetic fine mapping and genomic annotation defines causal mechanisms at type 2 diabetes susceptibility loci. Nat. Genet. 47, 1415-1425 (2015).

39. Williams, K. et al. Skeletal muscle enhancer interactions identify genes controlling whole-body metabolism. Nat. Commun. 11, (2020). 
medRxiv preprint doi: https://doi.org/10.1101/2021.10.11.21264235; this version posted October 14, 2021. The copyright holder for this preprint (which was not certified by peer review) is the author/funder, who has granted medRxiv a license to display the preprint in It is made available under a CC-BY 4.0 International license .

40. Tyrrell, J. S., Yaghootkar, H., Freathy, R. M., Hattersley, A. T. \& Frayling, T. M. Parental diabetes and birthweight in 236030 individuals in the UK Biobank study. Int. J. Epidemiol. 42, 1714-1723 (2013).

41. Warrington, N. M. et al. Maternal and fetal genetic effects on birth weight and their relevance to cardio-metabolic risk factors. Nat. Genet. 51, 804-814 (2019).

42. GTEx Consortium. The GTEx Consortium atlas of genetic regulatory effects across human tissues. Science 369, 1318-1330 (2020).

43. Guo, C. et al. Coordinated regulatory variation associated with gestational hyperglycaemia regulates expression of the novel hexokinase HKDC1. Nat. Commun. 6, (2015).

44. Khan, M. W., Priyadarshini, M., Cordoba-Chacon, J., Becker, T. C. \& Layden, B. T. Hepatic hexokinase domain containing 1 (HKDC1) improves whole body glucose tolerance and insulin sensitivity in pregnant mice. Biochim. Biophys. Acta - Mol. Basis Dis. 1865, 678687 (2019).

45. Hemani, G. et al. The MR-base platform supports systematic causal inference across the human phenome. Elife 7, (2018).

46. Yuan, S. \& Larsson, S. C. An atlas on risk factors for type 2 diabetes: a wide-angled Mendelian randomisation study. Diabetologia 63, 2359-2371 (2020). 